\title{
Nanophthalmos: A Review of the Clinical Spectrum and Genetics
}

\author{
Pedro C. Carricondo (D, ${ }^{1}$ Thais Andrade, ${ }^{1}$ Lev Prasov, ${ }^{2}$ Bernadete M. Ayres, ${ }^{2}$ \\ and Sayoko E. Moroi ${ }^{2}$ \\ ${ }^{1}$ Department of Ophthalmology, Hospital das Clínicas HCFMUSP, Faculdade de Medicina, Universidade de São Paulo, \\ São Paulo, SP, Brazil \\ ${ }^{2}$ Department of Ophthalmology and Visual Sciences, Kellogg Eye Center, University of Michigan, 1000 Wall St., \\ Ann Arbor, MI 48105, USA \\ Correspondence should be addressed to Pedro C. Carricondo; pedro.carricondo@gmail.com
}

Received 11 December 2017; Revised 20 February 2018; Accepted 8 April 2018; Published 9 May 2018

Academic Editor: Lisa Toto

Copyright (C) 2018 Pedro C. Carricondo et al. This is an open access article distributed under the Creative Commons Attribution License, which permits unrestricted use, distribution, and reproduction in any medium, provided the original work is properly cited.

\begin{abstract}
Nanophthalmos is a clinical spectrum of disorders with a phenotypically small but structurally normal eye. These disorders present significant clinical challenges to ophthalmologists due to a high rate of secondary angle-closure glaucoma, spontaneous choroidal effusions, and perioperative complications with cataract and retinal surgeries. Nanophthalmos may present as a sporadic or familial disorder, with autosomal-dominant or recessive inheritance. To date, five genes (i.e., MFRP, TMEM98, PRSS56, BEST1, and CRB1) and two loci have been implicated in familial forms of nanophthalmos. Here, we review the definition of nanophthalmos, the clinical and pathogenic features of the condition, and the genetics of this disorder.
\end{abstract}

\section{Introduction}

The clinical spectrum of the small eye phenotype comprises conditions in which there is a global ocular reduction in size (e.g., microphthalmos and nanophthalmos) or shortening of either the anterior or posterior segments of the eye (e.g., relative anterior and posterior microphthalmos, resp.) (Table 1) [1-3]. The axial length and anterior chamber structures present a continuum of sizes (Table 2), where microphthalmos and nanophthalmos comprise the smallest or shortest eyes. Nanophthalmos derives from Greek "dwarf eye." In this ocular condition, the anterior and posterior segments have no other congenital malformations, but are both reduced in size, with secondary thickening of choroid and sclera.

The management of the small eye phenotype represents a major challenge for all ophthalmologists, from cataract surgeons to glaucoma and retina specialists. Small eyes may be associated with ophthalmic or systemic comorbidities. These eyes represent significant surgical challenges with a very high rate of intraoperative complications [4] and require a surgical approach that involves precision and care.
Recognizing and correctly diagnosing the diverse presentations of this condition is of great importance for appropriate clinical and surgical management. Understanding the genetic mechanisms involved in the pathogenesis of nanophthalmos will ultimately help us to provide potential markers for genetic diagnosis and development of innovative therapies for this condition. The goal of this review is to define nanophthalmos and provide a brief summary of the advances in the clinical characterization and genetic basis for nanophthalmos.

\section{Methods}

A Medline/PubMed search was performed using the terms "nanophthalmos," "ocular development," and "genetics" and their combinations. All studies published in English, Portuguese, or Spanish up to December 2017 were reviewed, and relevant publications were included in this review. The pertinent references of the selected articles were also included. All patient images were obtained with the permission of participating individuals or from parents of minor patients, as part of a study on nanophthalmos. This study 
TABLE 1: The clinical spectrum of the small eye phenotype.

\begin{tabular}{lc}
\hline Anophthalmia & Absence of the eye \\
\hline $\begin{array}{l}\text { Simple } \\
\text { microphthalmos }\end{array}$ & $\begin{array}{c}\text { Short axial length due to global eye } \\
\text { reduction with no other findings }\end{array}$ \\
\hline $\begin{array}{l}\text { Complex } \\
\text { microphthalmos }\end{array}$ & $\begin{array}{c}\text { Short axial length due to global eye } \\
\text { reduction and associated ocular } \\
\text { malformations (e.g., colobomas, persistent } \\
\text { fetal vasculature, retinal dysplasia) }\end{array}$ \\
\hline $\begin{array}{l}\text { Relative anterior } \\
\text { microphthalmos }\end{array}$ & $\begin{array}{c}\text { Short axial length due to reduced anterior } \\
\text { chamber dimension only, with normal } \\
\text { posterior segment dimension and normal } \\
\text { scleral thickness }\end{array}$ \\
\hline $\begin{array}{l}\text { Posterior } \\
\text { microphthalmos }\end{array}$ & $\begin{array}{c}\text { Short axial length due to reduced posterior } \\
\text { segment dimension with normal anterior } \\
\text { chamber dimensions }\end{array}$ \\
\hline Nanophthalmos & $\begin{array}{c}\text { Short axial length due to small anterior and } \\
\text { posterior segments with thickened choroid } \\
\text { and sclera and normal lens volume }\end{array}$ \\
\hline
\end{tabular}

was approved by the University of Michigan Institutional Review Board and complied with the US Health Insurance Portability and Accountability Act of 1996 and the Declaration of Helsinki.

\section{Nanophthalmos: Definition and Clinical Features}

Microphthalmos is a developmental disorder of the eye characterized by an axial length of at least 2 standard deviations below the mean for age [1]. This condition is classified as simple, when presented as an isolated finding, or complex, when accompanied by other malformations such as colobomas, anterior segment dysgenesis, lens abnormalities, and posterior segment anomalies [1]. It may also appear as a syndrome with other systemic features. These malformations result from a variety of genetic defects that induce abnormalities in early ocular embryogenesis [9-13].

Nanophthalmos is a special subtype of microphthalmia, in which the eye, although small, has preserved functionality and organization (Figure 1) $[13,14]$. It usually presents as a small hyperopic eye set into a deep orbit, with narrow palpebral fissures $[15,16]$. A high hypermetropic refractive error is an invariable feature, ranging from $+8.00 \mathrm{D}$ sphere to +25.00 or higher $[2,17]$. However, the diagnostic criteria vary widely across the literature and considering only one parameter is simplistic. Wu et al. considered shallow anterior chamber, high hyperopia, axial length up to $21 \mathrm{~mm}$, and posterior wall thickness greater than $1.7 \mathrm{~mm}$ as conditions to define nanophthalmic eyes [18]. Similarly, Yalvac et al. considered the same characteristics (with axial length defined as less than $20.5 \mathrm{~mm}$ ) as diagnostic criteria but also added the high lens/eye volume ratio [19].

Another diagnostic issue that has been debated in the literature is the distinction between nanophthalmos and posterior microphthalmos. Posterior microphthalmos is described as a subtype of microphthalmia, in which the axial length is shortened in the posterior segment only. In this condition, the anterior segment of the eye has normal depth and angle configuration. Some investigators consider that nanophthalmos and posterior microphthalmos are synonymous [20]. The report that the reduction of the corneal diameter in high hyperopia is proportional to the axial shortening of the eye supports the hypothesis that these entities represent manifestations of the spectrum of hyperopia, rather than two completely different conditions. In addition, the fact that mutations in the same genes may cause both posterior microphthalmos and nanophthalmos reinforces this idea $[20,21]$.

However, other groups point to the clinical and structural differences between these conditions, such as the cornea size and curvature, anterior chamber depth, lens thickness, angle characteristics, and propensity for complications [2, 3, 20]. Relhan et al. [2] biometrically analyzed eyes of 38 patients with high hyperopia (defined in the study as greater than $+7.00 \mathrm{D}$ spherical equivalent on refraction), all of them with an axial length equal or less than $20.5 \mathrm{~mm}$. In this study, they defined the patients with corneal diameters below $11.0 \mathrm{~mm}$ as nanophthalmic and those with corneal diameters greater than or equal to $11.0 \mathrm{~mm}$ as posterior microphthalmos. They found that nanophthalmic eyes have shallow anterior chamber depth, thicker lens, and steeper cornea, in comparison with posterior microphthalmic eyes [2]. They also reported different tendencies to complications: the incidence of angle-closure glaucoma was $69.23 \%$ in the nanophthalmos group versus $0 \%$ in the posterior microphthalmos group, while the incidence of macular folds was $0 \%$ versus $24 \%$, respectively [2].

In addition to these clinical features, nanophthalmic eyes have abnormal collagen fibrils in each of the three layers of the sclera [22]. These abnormal fibers are thought to be the cause for the increase scleral thickness as mentioned above (Figure 1). In addition, the combination of increased scleral thickness and abnormal collagen also contributes to its inelasticity, which impairs vortex venous drainage and reduces transcleral flow of proteins [22]. These histopathologic features and anatomy described above are thought to be the mechanism by which nanophthalmic eyes develop complications of angle-closure glaucoma, uveal effusion syndrome, and retinal detachment [19, 22-28]. However, it is unclear whether the abnormal scleral structure is a primary or secondary effect of the genetic changes that induce nanophthalmos as many of the genes implicated in this condition are expressed in retina and retinal pigment epithelium [14, 29-32].

Other ocular findings include topographic corneal steepening and irregular astigmatism [33], absent or rudimentary foveal avascular zone [34], optic disc drusen, retinoschisis and foveoschisis and retinitis pigmentosa (RP) $[35,36]$, crowded optic disk, chorioretinal folds, and retinal cysts [37], central retinal vein occlusion [38], increased subfoveal choroidal thickness [39], and abnormalities in the retinal layers' thickness and distribution [40, 41] (Figure 1).

In summary, the described anatomical features and histopathology of the nanophthalmic eye explain the severe visual consequences in individuals with nanophthalmos. If the axial hyperopia is not corrected in early childhood, 
TABLE 2: Clinical spectrum of eye size phenotypes based on axial length [5] and anterior segment features by anterior chamber depth and white-to-white corneal diameter [6-8].

\begin{tabular}{lcccc}
\hline & & Axial length & & \\
& & Short $(<21 \mathrm{~mm})$ & Average $(24 \mathrm{~mm})$ & Long $(>27 \mathrm{~mm})$ \\
\hline $\begin{array}{c}\text { Anterior } \\
\text { segment }\end{array}$ & $($ Small & $\begin{array}{c}\text { Microphthalmos and } \\
\text { nanophthalmos } \\
\text { Heropia posterior } \\
\text { microphthalmos }\end{array}$ & $\begin{array}{c}\text { Relative anterior } \\
\text { microphthalmos }\end{array}$ & Complex dysgenesis \\
& Average & Normal & Myopia \\
Large & Complex dysgenesis & Megalocornea & $\begin{array}{c}\text { Infantile or congenital } \\
\text { glaucoma myopia }\end{array}$ \\
\hline
\end{tabular}

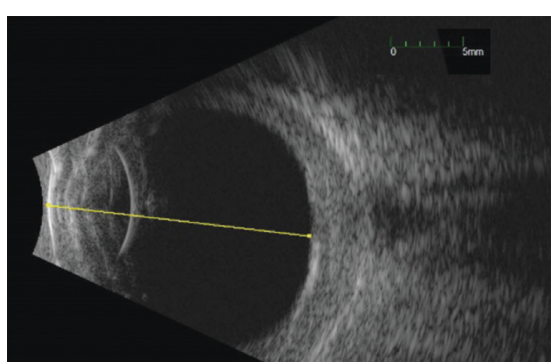

(a)

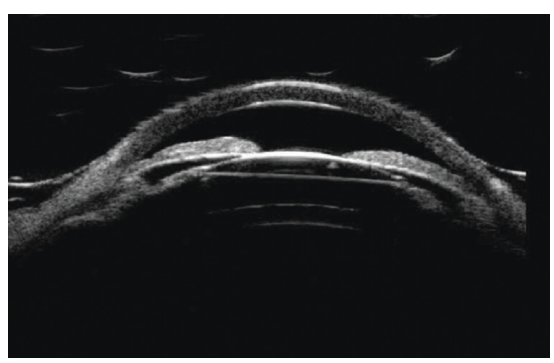

(d)

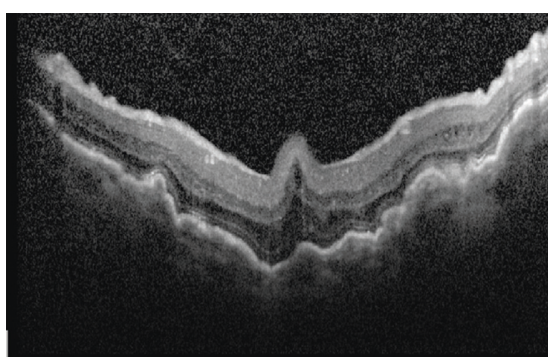

(g)

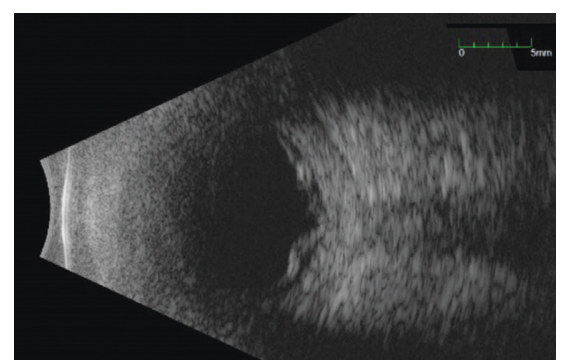

(b)

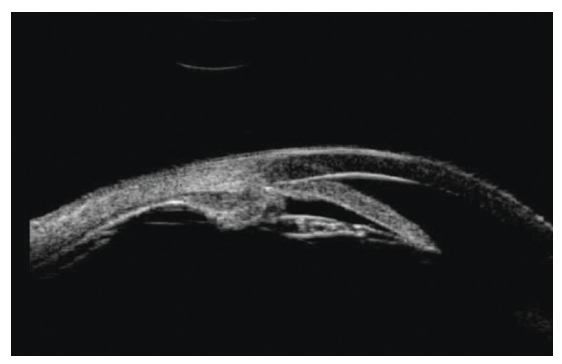

(e)

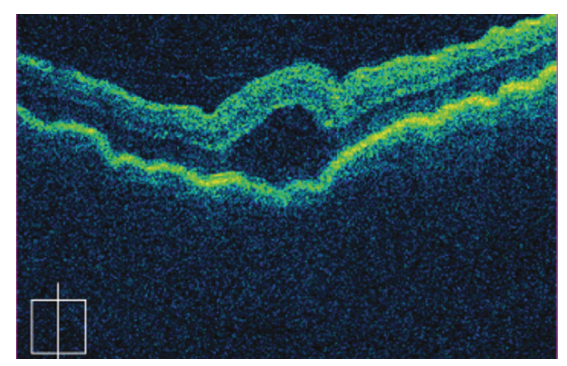

(h)

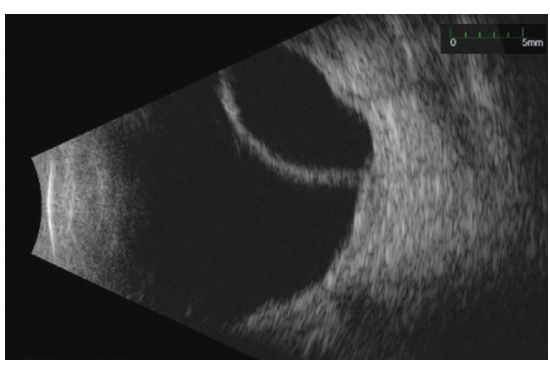

(c)

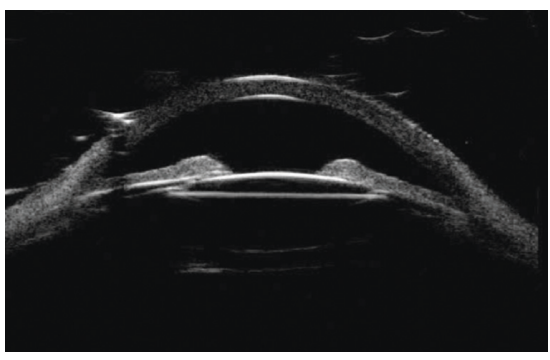

(f)

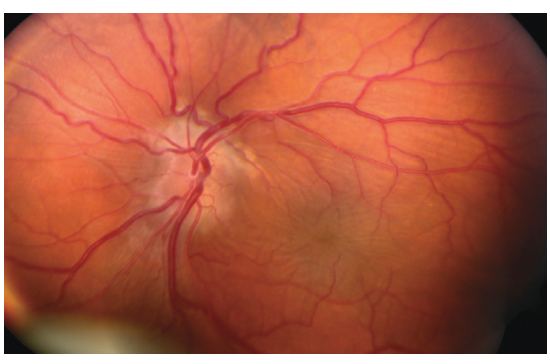

(i)

FIgURE 1: Typical ultrasonographic and retinal features of nanophthalmos. (a-c) B-scan ultrasounds showing features of nanophthalmos including short axial length, thickened sclera, and choroid (a), serous retinal detachment (b), and choroidal effusion (c). (d-f) Ultrasound biomicroscopy in a nanophthalmic eyes showing shallow anterior chamber (d), angle closure (e), and anterior rotation of the lens-iris diaphragm (f). (g) Heidelberg Spectralis OCT showing prominent choroidal and retinal folds in a small eye. (h) Zeiss Cirrus OCT showing foveoschisis and choroidal folds in a nanophthalmic eye. (i) Fundus photos in a patient with nanophthalmos and optic disc drusen, showing chorioretinal folds and crowded disc with mild vascular tortuousity.

then this results in irreversible amblyopia. The unrecognized and untreated angle-closure glaucoma can lead to progressive optic nerve damage and blindness [26]. Furthermore, intraocular surgeries in nanophthalmic eyes have significant risks and complications, both intraoperatively and postoperatively $[3,25,42,43]$. Proper preoperative planning and anatomic understanding can lead to good outcomes and improved quality of life in these patients [18], despite a nearly $40-60 \%$ rate of intraoperative complications $[4,22,44,45]$.

\section{Genetic Aspects of Nanophthalmos}

Nanophthalmos occurs due to arrested development of the eye in the early stages of embryogenesis. It is thought to have a strong genetic basis. There are many reported familial cases 
TABLE 3: Genes and phenotypes in nanophthalmos.

\begin{tabular}{|c|c|c|c|c|c|c|}
\hline Gene (locus) & OMIM & Location & Inheritance & $\begin{array}{l}\text { Gene expression } \\
\text { (localization) }\end{array}$ & Gene function & Phenotypic characteristics of mutations \\
\hline $\begin{array}{l}\text { MFRP } \\
(\mathrm{NNO} 2)\end{array}$ & 606227 & $11 \mathrm{q} 23.3$ & $\mathrm{AR}$ & $\begin{array}{c}\mathrm{RPE} / \mathrm{CB} \\
\text { (transmembrane) }\end{array}$ & $\begin{array}{l}\text { Wnt signalling } \\
\text { pathway } \\
\text { effector }\end{array}$ & $\begin{array}{l}\text { (i) Nanopthalmos, high hyperopia, } \\
\text { and angle-closure glaucoma } \\
\text { (ii) Retinitis pigmentosa, foveoschisis, } \\
\text { and optic disc drusen syndrome }\end{array}$ \\
\hline $\begin{array}{l}\text { TMEM98 } \\
\text { (NNO4) }\end{array}$ & 615949 & $17 \mathrm{q} 11.2$ & $\mathrm{AD}$ & $\begin{array}{c}\mathrm{RPE} / \mathrm{CB} / \text { sclera } \\
\text { (transmembrane) }\end{array}$ & Unknown & $\begin{array}{l}\text { (i) High hyperopia, angle-closure glaucoma, } \\
\text { and increased optic disc drusen }\end{array}$ \\
\hline $\begin{array}{l}\text { PRSS56 } \\
(\text { MCOP6) }\end{array}$ & 613858 & $2 \mathrm{q} 37.1$ & $\mathrm{AR}$ & $\begin{array}{l}\text { Retina/sclera } \\
\text { (cytoplasmic) }\end{array}$ & $\begin{array}{l}\text { Serine } \\
\text { protease }\end{array}$ & $\begin{array}{l}\text { (i) Nanophthalmos, angle-closure glaucoma, } \\
\text { and high hyperopia } \\
\text { (ii) Posterior microphthalmia }\end{array}$ \\
\hline CRB1 & 604210 & $1 \mathrm{q} 31.3$ & $\mathrm{AR}$ & $\begin{array}{c}\text { Retina } \\
\text { (transmembrane) }\end{array}$ & $\begin{array}{l}\text { Controls cell } \\
\text { polarity }\end{array}$ & $\begin{array}{l}\text { (i) Nanophthalmos and retinitis pigmentosa } \\
\text { (ii) Leber congenital amaurosis } 8 \\
\text { (iii) Pigmented paravenous chorioretinal } \\
\text { atrophy } \\
\text { (iv) Retinitis pigmentosa }\end{array}$ \\
\hline Best1/VMD2 & 607854 & $11 \mathrm{q} 12$ & $\mathrm{AD}$ or $\mathrm{AR}$ & $\begin{array}{c}\mathrm{RPE} / \mathrm{CB} \\
\text { (transmembrane) }\end{array}$ & $\begin{array}{l}\text { Chloride } \\
\text { channel }\end{array}$ & $\begin{array}{l}\text { (i) ADVIRC: autosomal-dominant } \\
\text { vitreoretinochoroidopathy with nanophthalmos } \\
\text { (ii) ARB: autosomal-recessive bestrophinopathy } \\
\text { (iii) BVMD: best vitelliform macular dystrophy }\end{array}$ \\
\hline $\begin{array}{l}\text { Unknown } \\
\text { (NNO3) }\end{array}$ & 611897 & $2 \mathrm{q} 11-\mathrm{q} 14$ & $\mathrm{AD}$ & & & $\begin{array}{l}\text { (i) Microphthalmia, microcornea, and high } \\
\text { hyperopia }\end{array}$ \\
\hline $\begin{array}{l}\text { Unknown } \\
\text { (NNO1) }\end{array}$ & 600165 & $\begin{array}{l}11 \mathrm{p} 12- \\
11 \mathrm{q} 13\end{array}$ & $\mathrm{AD}$ & & & $\begin{array}{l}\text { (i) High hyperopia, high lens/eye volume ratio, } \\
\text { and angle-closure glaucoma }\end{array}$ \\
\hline
\end{tabular}

RPE: retinal pigment epithelium; CB: ciliary body.

with autosomal-dominant and recessive forms of inheritance $[26,30,46,47]$. However, nanophthalmos can also occur as a sporadic condition [23, 28, 48, 49], which may represent either environmental effects or somatic or new mutations that result in arrest of ocular growth.

To date, five genetic loci (Table 3 ) were reported to be linked to nanophthalmos: NNOS 2 is related to mutations in membrane frizzled-related protein $(M F R P)$; NNOS 4 is related to mutations in TMEM98; MCOP6 is related to mutations in serine protease 56 (PRSS56) [50, 51]; and NNOS 1 and 3 were localized to chromosomal regions only (11p12-11q13 and 2q11-q14) [26, 29, 30]. Two additional genes, CRB1 and BEST1 (VMD2), have been implicated in nanophthalmos (Table 3) and have profound roles in photoreceptor and retinal pigment epithelial (RPE) function, respectively.

4.1. Membrane-Type Frizzled-Related Protein Gene (MFRP). A significant number of cases of recessive nanophthalmos have been assigned to mutations in the membrane-type frizzled-related protein gene (MFRP, OMIM 606227) [29]. This gene is located in chromosome 11q23 and encodes a glycosylated transmembrane protein that has an extracellular frizzled-related cysteine-rich domain. Frizzled proteins are receptors involved in the regulation of growth, differentiation, and cell polarity during development through the Wnt signaling pathway $[52,53]$.

In humans, the MFRP gene is expressed in the retinal pigment epithelium and in the ciliary body [14, 29]. Outside of the eye, it can only be found at very low levels in the brain, likely accounting for the localized ocular phenotype in MFRP deficiency [29]. This gene seems to play an important role in both the ocular growth during childhood, functioning as a regulator of ocular size. It also has a role in maintenance of the RPE, which supports photoreceptor function [14, 54-56]. Mouse models of MFRP deficiency, such as $\operatorname{rd6}\left(\mathrm{Mfrp}^{\mathrm{rd} 6}\right)$ and $\mathrm{rdx}\left(\mathrm{Mfrp}^{174 \mathrm{delG}}\right)$ mice, have flecked retina disorders and photoreceptor degeneration, supporting the importance of this gene for retinal and RPE physiology [57-60].

The link between eye size and RPE/ciliary body function has yet to be elucidated. It has been proposed that MFRP affects the physiologic mechanism of emmetropization, in which the refractive error is corrected by postnatal axial growth during the first six years of life [14]. Soundrarajan suggested that a complex regulatory network may influence the postnatal eye development and indicated the participation of another gene (PRSS56) in the same pathway [61]. Besides these, other proposed mechanisms for the role of the $\mathrm{RPE} /$ ciliary body in eye size include the mechanical stress effects and the inflammatory response observed in the retina [14, 62, 63]. Most recently, Velez et al. [64] found that introducing a normal copy of Mfrp gene through adenoviralbased gene therapy may reverse some of these pathogenic changes in Mfrp $r d 6 / r d 6$ mice. Specifically, subretinal injection of this vector resulted in rescue of photoreceptor death, normalization of retinal function, and regulation of eye length in adult mice. These findings suggest that gene therapy may be a viable option for this disease.

Mouse models of Mfrp loss-of-function have failed to demonstrate the full nanophthalmic phenotype observed in 
humans and instead present with predominant retinal degeneration [57-60]. This may be in part due to the differences in the lens size and ocular anatomy in mice and humans. Collery et al. proposed a new model using zebrafish (Danio rerio) that better mimics the human phenotype and may be useful in studying and better understanding this condition [62].

To date, several cases of MFRP mutations leading to reduced eye axial length have been reported. According to Wasmann et al. [65], by the time of the publication in 2014, there were 14 different described MFRP mutations: two of them were single amino acid substitutions at extremely conserved sites and 12 caused severe truncation of the protein. Since that time, three new mutations have been described [55], and additional known mutations have been reported in other populations $[36,66]$. All of these cases presented with high hyperopia, but the effect of the mutation on retinal rod photoreceptor function was different between individuals, and the clinical spectrum of age of onset and severity of disease was quite variable [65]. The reason for this clinical variability may be a combination of the spectrum of genetic mutations in MFRP and other genetic or environmental modifiers that remain to be determined [67].

Wasmann et al. reported a case of two sisters with confirmed MFRP mutations. They both presented low visual acuity, high hyperopia, macular retinal folds, with the older sibling also having thickened sclera, and optic nerve head drusen [65]. The mutations in the MFRP gene have also been linked to the autosomal-recessive syndrome of posterior microphthalmos, retinitis pigmentosa, foveoschisis, and optic disc drusen $[29,35,66-68]$. These results represent the broad clinical spectrum of MFRP mutations, which occurs likely due to differences in early gene expression and environmental factors that shape the development of the eye.

\subsection{Transmembrane Protein 98 Gene (TMEM98). The trans-} membrane protein 98 (TMEM98, OMIM 615949) gene encodes a transmembrane protein that is universally expressed in the human body, including in the ocular tissues, such as iris, choroid, retinal pigment epithelium, and sclera. Its specific function still remains unclear, but it is hypothesized to lead to pathologic scleral pathologic thickening and secondary glaucoma development in nanophthalmic eyes or play a role in the development of the RPE [30, 31].

In a large pedigree, Awadalla and coworkers found a missense mutation in the TMEM98 (A193P) that could be associated with autosomal-dominant nanophthalmos [30]. Although its pathogenic relationship with the disease was not clear, this association has been greatly strengthened by Khorram and colleagues' recent report of two novel TMEM98 mutations (His196Pro and c.694_721delAG AATGAAGACTGGATCGAAGATGCCTCgtaagg) in autosomaldominant nanophthalmic patients [31]. Additional studies are still needed to identify the specific role of this gene in the pathogenesis of nanophthalmos.

4.3. Protease Serine 56 (PRSS56). PRSS56, also known as LOC646960, is located in the chromosome 2q37.1 and encodes a protein of 603 amino acids, which functions as a serine protease. It is suggested that it is expressed in the embryonic tissue, brain, testis, and eye [50]. There are reports of its association with nanophthalmos and posterior microphthalmos cases [21, 50,69] although its physiologic and pathogenic mechanisms remain to be fully determined [21].

It has been reported that PRSS56 is highly expressed in retinal ganglion cells of adult animals [50], and its presence in this tissue and in the brain cells suggest its relevance in the regulation of ocular development [69]. Nair et al. [51] demonstrated this role in the homozygous mutant mice Prss56 ${ }^{\mathrm{Grm} 4}$, which showed shortened axial length and higher susceptibility to angle closure. Furthermore, they found that the differences in ocular size between mutant mice and wildtype controls were progressively greater after birth, with no significant difference prior to that time [51]. They found that the genetic background had a strong influence of magnitude of eye size differences between wild-type and mutant mice, suggesting the existence of genetic modifiers that influence eye growth in concert with Prss56. Soundararajan et al. also suggested that PRSS56 and MFRP may function through a common biological pathway that affects the emmetropization process, but nature of this interaction is still unclear [61].

4.4. Crumbs Homologue 1 Gene (CRB1). Human CRB1 is a 1406 amino acids transmembrane protein that localizes to photoreceptor inner segments and is vital for the neuronal development of the retina [70,71]. The CRB1 gene is located in chromosome 1, in the interval 1q31.2-1q32.1, and its mutations are classically associated with various heritable retinal dystrophies, including Leber Congenital Amaurosis $[70,72,73]$. Furthermore, some recent reports showed association of mutation in CRB1 with nanophthalmos and retinitis pigmentosa $[74,75]$.

4.5. Bestrophin 1 (BEST1/VMD2). The BEST1 (VMD2) gene is located on chromosome 11q12 and is primarily expressed in the RPE [32]. It encodes an integral membrane protein, bestrophin 1 , localized predominantly in the basolateral plasma membrane of the RPE and most prominently near the macula $[76,77]$. BEST1 mutations are classically associated with Best vitelliform macular dystrophy (BVMD), a disease restricted to the macula. However, it has been reported to be in association with other widespread ocular abnormalities, such as autosomal-dominant vitreoretinochoroidopathy (ADVIRC) and autosomal-recessive bestrophinopathy (ARB), which are both associated with nanophthalmos [76]. Other studies also strongly suggest an association between BEST1 mutations and angle-closure glaucoma [77, 78].

ADVIRC is a rare condition characterized by a peripheral circumferential hyperpigmented band with punctate white opacities in the retina, chorioretinal atrophy in the midperipheral or peripapillary retina, and vitreous fibrillary condensations [76, 79]. There are reports of association of this condition with nanophthalmos and a higher incidence of angle-closure glaucoma [79, 80].

ARB is also a rare condition characterized by macular and midperipheral subretinal whitish to yellowish deposits 
that may become scars and lead to decrease in visual acuity [81-83]. Patients are usually hyperopic and have a shallow anterior chamber and a higher propensity to angle-closure glaucoma [81-85].

4.6. Other Loci for Nanophthalmos. The autosomaldominant nanophthalmos NNO1 (OMIM 600165) is caused by a defect on chromosome 11, between D11S905 and D11S987. This region may also be associated with severity of angle-closure glaucoma manifestations [26]. The precise genetic change at this locus has yet to be confirmed, though coding and regulatory mutations in BEST1 have been excluded as a cause (data not shown). Another form of autosomal-dominant disease, NNO3 (OMIM 611897), was described in a family with simple microphthalmia, microcornea, and high hyperopia, and it was reported to be linked to chromosome 2q11-14 [86].

\section{Conclusion}

With the progress of the imaging and surgical technologies, there have been significant advances in the diagnosis and management of the nanophthalmic eye. These have improved outcomes for individuals with such challenging eyes. Furthermore, substantial new discoveries in the genetics of nanophthalmos have led to the discovery of many new genes and pathways in the pathogenesis of this condition. These advances will ultimately improve early detection of this condition and provide novel avenues for treatment, including the possibility for gene therapy. Genetic diagnoses will facilitate genetic counseling for familial forms of this condition and may help to decrease amblyopia from uncorrected hyperopia, prevent vision loss from complications, and improve monitoring to minimize glaucoma and retinal complications from nanophthalmos.

\section{Conflicts of Interest}

The authors declare that they have no conflicts of interest.

\section{Acknowledgments}

This work was supported in part by a Career Starter Award from the Knights Templar Eye Foundation to Lev Prasov. The authors thank the clinicians and the photographers who participated in the care of these patients at the Kellogg Eye Center at the University of Michigan.

\section{References}

[1] M. J. Elder, "Aetiology of severe visual impairment and blindness in microphthalmos," British Journal of Ophthalmology, vol. 78, no. 5, pp. 332-334, 1994.

[2] N. Relhan, S. Jalali, N. Pehre, H. L. Rao, U. Manusani, and L. Bodduluri, "High-hyperopia database, part I: clinical characterisation including morphometric (biometric) differentiation of posterior microphthalmos from nanophthalmos," Eye, vol. 30, no. 1, pp. 120-126, 2016.
[3] R. S. Hoffman, A. R. Vasavada, Q. B. Allen et al., "Cataract surgery in the small eye," Journal of Cataract and Refractive Surgery, vol. 41, no. 11, pp. 2565-2575, 2015.

[4] S. Rajendrababu, N. Babu, S. Sinha et al., "A randomized controlled trial comparing outcomes of cataract surgery in nanophthalmos with and without prophylactic sclerostomy," American Journal of Ophthalmology, vol. 183, pp. 125-133, 2017.

[5] M. De Bernardo, L. Zeppa, R. Forte et al., "Can we use the fellow eye biometric data to predict IOL power?," Seminars in Ophthalmology, vol. 32, no. 3, pp. 363-370, 2017.

[6] G. U. Auffarth, M. Blum, U. Faller, M. R. Tetz, and H. E. Volcker, "Relative anterior microphthalmos: morphometric analysis and its implications for cataract surgery," Ophthalmology, vol. 107, no. 8, pp. 1555-1560, 2000.

[7] M. Khairallah, R. Messaoud, S. Zaouali, S. Ben Yahia, A. Ladjimi, and S. Jenzri, "Posterior segment changes associated with posterior microphthalmos," Ophthalmology, vol. 109, no. 3, pp. 569-574, 2002.

[8] I. Guber, C. Bergin, S. Perritaz, and F. Majo, "Correcting interdevice bias of horizontal white-to-white and sulcus-tosulcus measures used for implantable collamer lens sizing," American Journal of Ophthalmology, vol. 161, pp. 116-125 e1, 2016.

[9] A. M. Slavotinek, "Eye development genes and known syndromes," Molecular Genetics and Metabolism, vol. 104, no. 4, pp. $448-456,2011$.

[10] T. M. Bardakjian and A. Schneider, "The genetics of anophthalmia and microphthalmia," Current Opinion in Ophthalmology, vol. 22, no. 5, pp. 309-313, 2011.

[11] D. R. Fitzpatrick and V. van Heyningen, "Developmental eye disorders," Current Opinion in Genetics and Development, vol. 15, no. 3, pp. 348-353, 2005.

[12] M. Warburg, "Classification of microphthalmos and coloboma," Journal of Medical Genetics, vol. 30, no. 8, pp. 664669, 1993.

[13] A. S. Verma and D. R. Fitzpatrick, "Anophthalmia and microphthalmia," Orphanet Journal of Rare Diseases, vol. 2, p. 47, 2007.

[14] O. H. Sundin, S. Dharmaraj, I. A. Bhutto et al., "Developmental basis of nanophthalmos: MFRP is required for both prenatal ocular growth and postnatal emmetropization," Ophthalmic Genetics, vol. 29, no. 1, pp. 1-9, 2008.

[15] O. S. Singh, R. J. Simmons, R. J. Brockhurst, and C. L. Trempe, "Nanophthalmos: a perspective on identification and therapy," Ophthalmology, vol. 89, no. 9, pp. 1006-1012, 1982.

[16] A. K. Altintaş, M. A. Acar, I. S. Yalvaç, I. Koçak, A. Nurözler, and S. Duman, "Autosomal recessive nanophthalmos," Acta Ophthalmologica Scandinavica, vol. 75, no. 3, pp. 325-328, 1997.

[17] A. O. Khan, "Posterior microphthalmos versus nanophthalmos," Ophthalmic Genetics, vol. 29, no. 4, p. 189, 2008.

[18] W. Wu, D. G. Dawson, A. Sugar et al., "Cataract surgery in patients with nanophthalmos: results and complications," Journal of Cataract and Refractive Surgery, vol. 30, no. 3, pp. 584-590, 2004.

[19] I. S. Yalvac, B. Satana, G. Ozkan, U. Eksioglu, and S. Duman, "Management of glaucoma in patients with nanophthalmos," Eye, vol. 22, no. 6, pp. 838-843, 2008.

[20] S. R. Nowilaty, A. O. Khan, M. A. Aldahmesh, K. F. Tabbara, A. Al-Amri, and F. S. Alkuraya, "Biometric and molecular characterization of clinically diagnosed posterior microphthalmos," American Journal of Ophthalmology, vol. 155, no. 2, pp. 361-372.e7, 2013. 
[21] M. B. Said, E. Chouchène, S. B. Salem et al., "Posterior microphthalmia and nanophthalmia in Tunisia caused by a founder c.1059_1066insC mutation of the PRSS56 gene," Gene, vol. 528, no. 2, pp. 288-294, 2013.

[22] A. Yamani, I. Wood, I. Sugino, M. Wanner, and M. A. Zarbin, "Abnormal collagen fibrils in nanophthalmos: a clinical and histologic study," American Journal of Ophthalmology, vol. 127, no. 1, pp. 106-108, 1999.

[23] Y. M. Buys and C. J. Pavlin, "Retinitis pigmentosa, nanophthalmos, and optic disc drusen: a case report," Ophthalmology, vol. 106, no. 3, pp. 619-622, 1999.

[24] A. Neelakantan, P. Venkataramakrishnan, B. S. Rao et al., "Familial nanophthalmos: management and complications," Indian Journal of Ophthalmology, vol. 42, no. 3, pp. 139-143, 1994.

[25] E. Areiter, M. Neale, and S. M. Johnson, "Spectrum of angle closure, uveal effusion syndrome, and nanophthalmos," Journal of Current Glaucoma Practice, vol. 10, no. 3, pp. 113-117, 2016.

[26] M. I. Othman, S. A. Sullivan, G. L. Skuta et al., "Autosomal dominant nanophthalmos (NNO1) with high hyperopia and angle-closure glaucoma maps to chromosome 11," American Journal of Human Genetics, vol. 63, no. 5, pp. 1411-1418, 1998.

[27] N. Kara, O. Baz, H. Altinkaynak, C. Altan, and A. Demirok, "Assessment of the anterior chamber angle in patients with nanophthalmos: an anterior segment optical coherence tomography study," Current Eye Research, vol. 38, no. 5, pp. 563-568, 2013.

[28] A. K. Mandal, T. Das, and V. K. Gothwal, "Angle closure glaucoma in nanophthalmos and pigmentary retinal dystrophy: a rare syndrome," Indian Journal of Ophthalmology, vol. 49 , no. 4, pp. 271-272, 2001.

[29] O. H. Sundin, G. S. Leppert, E. D. Silva et al., "Extreme hyperopia is the result of null mutations in MFRP, which encodes a frizzled-related protein," Proceedings of the $\mathrm{Na}$ tional Academy of Sciences of the United States of America, vol. 102, no. 27, pp. 9553-9558, 2005.

[30] M. S. Awadalla, K. P. Burdon, E. Souzeau et al., "Mutation in TMEM98 in a large white kindred with autosomal dominant nanophthalmos linked to 17p12-q12," JAMA Ophthalmology, vol. 132, no. 8, pp. 970-977, 2014.

[31] D. Khorram, M. Choi, B. R. Roos et al., "Novel TMEM98 mutations in pedigrees with autosomal dominant nanophthalmos," Molecular Vision, vol. 21, pp. 1017-1023, 2015.

[32] K. Petrukhin, M. J. Koisti, B. Bakall et al., "Identification of the gene responsible for Best macular dystrophy," Nature Genetics, vol. 19, no. 3, pp. 241-247, 1998.

[33] S. Srinivasan, M. Batterbury, I. B. Marsh, A. C. Fisher, C. Willoughby, and S. B. Kaye, "Corneal topographic features in a family with nanophthalmos," Cornea, vol. 25, no. 6, pp. 750-756, 2006.

[34] M. K. Walsh and M. F. Goldberg, "Abnormal foveal avascular zone in nanophthalmos," American Journal of Ophthalmology, vol. 143, no. 6, pp. 1067-1068, 2007.

[35] J. Crespí, J. A. Buil, F. Bassaganyas et al., “A novel mutation confirms MFRP as the gene causing the syndrome of nanophthalmos-renititis pigmentosa-foveoschisis-optic disk drusen," American Journal of Ophthalmology, vol. 146, no. 2, pp. 323-328, 2008

[36] L. C. Zacharias, R. Susanna, O. Sundin, S. Finzi, B. N. Susanna, and W. Y. Takahashi, "Efficacy of topical dorzolamide therapy for cystoid macular edema in a patient with MFRP-related nanophthalmos-retinitis pigmentosa-foveoschisis-optic disk drusen syndrome," Retinal Cases and Brief Reports, vol. 9, no. 1, pp. 61-63, 2015.
[37] C. J. MacKay, M. S. Shek, R. E. Carr, L. A. Yanuzzi, and P. Gouras, "Retinal degeneration with nanophthalmos, cystic macular degeneration, and angle closure glaucoma. A new recessive syndrome," Archives of Ophthalmology, vol. 105, no. 3, pp. 366-371, 1987.

[38] A. A. Albar, S. R. Nowilaty, and N. G. Ghazi, "Nanophthalmos and hemiretinal vein occlusion: a case report," Saudi Journal of Ophthalmology, vol. 29, no. 1, pp. 89-91, 2015.

[39] A. Demircan, C. Altan, O. A. Osmanbasoglu, U. Celik, N. Kara, and A. Demirok, "Subfoveal choroidal thickness measurements with enhanced depth imaging optical coherence tomography in patients with nanophthalmos," British Journal of Ophthalmology, vol. 98, no. 3, pp. 345-349, 2014.

[40] H. Xiao, X. Guo, Y. Zhong, and X. Liu, "Retinal and choroidal changes of nanophthalmic eyes with and without secondary glaucoma," Retina, vol. 35, no. 10, pp. 2121-2129, 2015.

[41] F. Helvacioglu, Z. Kapran, S. Sencan, M. Uyar, and O. Cam, "Optical coherence tomography of bilateral nanophthalmos with macular folds and high hyperopia," Case Reports in Ophthalmological Medicine, vol. 2014, Article ID 173853, 3 pages, 2014.

[42] J. S. Chang, J. C. Ng, V. K. Chan, and A. K. Law, "Cataract surgery with a new fluidics control phacoemulsification system in nanophthalmic eyes," Case Reports in Ophthalmology, vol. 7, no. 3, pp. 218-226, 2016.

[43] S. Srinivasan, "Small eyes-big problems," Journal of Cataract and Refractive Surgery, vol. 41, no. 11, pp. 2345-2346, 2015.

[44] G. Carifi, F. Safa, F. Aiello, C. Baumann, and V. Maurino, "Cataract surgery in small adult eyes," British Journal of Ophthalmology, vol. 98, no. 9, pp. 1261-1265, 2014.

[45] H. Singh, J. C. Wang, D. C. Desjardins, K. Baig, S. Gagné, and I. I. Ahmed, "Refractive outcomes in nanophthalmic eyes after phacoemulsification and implantation of a high-refractivepower foldable intraocular lens," Journal of Cataract and Refractive Surgery, vol. 41, no. 11, pp. 2394-2402, 2015.

[46] S. Moradian, A. Kanani, and H. Esfandiari, "Nanophthalmos," Journal of Ophthalmic and Vision Research, vol. 6, no. 2, pp. 145-146, 2011.

[47] M. Martorina, "Familial nanophthalmos," Journal Français D’Ophtalmologie, vol. 11, no. 4, pp. 357-361, 1988.

[48] S. Ghose, M. S. Sachdev, and H. Kumar, "Bilateral nanophthalmos, pigmentary retinal dystrophy, and angle closure glaucoma-a new syndrome?," British Journal of Ophthalmology, vol. 69, no. 8, pp. 624-628, 1985.

[49] H. Proença, A. Castanheira-Dinis, and M. Monteiro-Grillo, "Bilateral nanophthalmos and pigmentary retinal dystrophy-an unusual syndrome," Graefe's Archive for Clinical and Experimental Ophthalmology, vol. 244, no. 9, pp. 1203-1205, 2006.

[50] A. Gal, I. Rau, L. El Matri et al., "Autosomal-recessive posterior microphthalmos is caused by mutations in PRSS56, a gene encoding a trypsin-like serine protease," American Journal of Human Genetics, vol. 88, no. 3, pp. 382-390, 2011.

[51] K. S. Nair, M. Hmani-Aifa, Z. Ali et al., "Alteration of the serine protease PRSS56 causes angle-closure glaucoma in mice and posterior microphthalmia in humans and mice," Nature Genetics, vol. 43, no. 6, pp. 579-584, 2011.

[52] P. Bhanot, M. Brink, C. H. Samos et al., "A new member of the frizzled family from drosophila functions as a wingless receptor," Nature, vol. 382, no. 6588, pp. 225-230, 1996.

[53] M. Katoh, "Molecular cloning and characterization of MFRP, a novel gene encoding a membrane-type frizzled-related protein," Biochemical and Biophysical Research Communications, vol. 282, no. 1, pp. 116-123, 2001. 
[54] M. Mameesh, A. Ganesh, B. Harikrishna et al., "Coinheritance of the membrane frizzled-related protein ocular phenotype and glycogen storage disease type Ib," Ophthalmic Genetics, vol. 38, no. 6, pp. 1-5, 2017.

[55] R. Mukhopadhyay, P. I. Sergouniotis, D. S. Mackay et al., "A detailed phenotypic assessment of individuals affected by MFRP-related oculopathy," Molecular Vision, vol. 16, pp. $540-548,2010$.

[56] M. N. Mandal, V. Vasireddy, M. M. Jablonski et al., "Spatial and temporal expression of MFRP and its interaction with CTRP5," Investigative Ophthalmology and Visual Science, vol. 47, no. 12, pp. 5514-5521, 2006.

[57] S. Kameya, N. L. Hawes, B. Chang, J. R. Heckenlively, J. K. Naggert, and P. M. Nishina, "Mfrp, a gene encoding a frizzled related protein, is mutated in the mouse retinal degeneration 6," Human Molecular Genetics, vol. 11, no. 16, pp. 1879-1886, 2002.

[58] J. Fogerty and J. C. Besharse, "174delG mutation in mouse MFRP causes photoreceptor degeneration and RPE atrophy," Investigative Ophthalmology and Visual Science, vol. 52, no. 10, pp. 7256-7266, 2011.

[59] N. L. Hawes, B. Chang, G. S. Hageman et al., "Retinal degeneration 6 (rd6): a new mouse model for human retinitis punctata albescens," Investigative Ophthalmology and Visual Science, vol. 41, no. 10, pp. 3149-3157, 2000.

[60] O. H. Sundin, "The mouse's eye and Mfrp: not quite human," Ophthalmic Genetics, vol. 26, no. 4, pp. 153-155, 2005.

[61] R. Soundararajan, J. Won, T. M. Stearns et al., "Gene profiling of postnatal Mfrprd6 mutant eyes reveals differential accumulation of Prss56, visual cycle and phototransduction mRNAs," PLoS One, vol. 9, no. 10, article e110299, 2014.

[62] R. F. Collery, P. J. Volberding, J. R. Bostrom, B. A. Link, and J. C. Besharse, "Loss of zebrafish Mfrp causes nanophthalmia, hyperopia, and accumulation of subretinal macrophages," Investigative Ophthalmology and Visual Science, vol. 57, no. 15 , pp. 6805-6814, 2016.

[63] P. Wang, Z. Yang, S. Li, X. Xiao, X. Guo, and Q. Zhang, "Evaluation of MFRP as a candidate gene for high hyperopia," Molecular Vision, vol. 15, pp. 181-186, 2009.

[64] G. Velez, S. H. Tsang, Y. T. Tsai et al., "Gene therapy restores Mfrp and corrects axial eye length," Scientific Reports, vol. 7, no. 1, p. 16151, 2017.

[65] R. A. Wasmann, J. S. Wassink-Ruiter, O. H. Sundin, E. Morales, J. B. Verheij, and J. W. Pott, "Novel membrane frizzled-related protein gene mutation as cause of posterior microphthalmia resulting in high hyperopia with macular folds," Acta Ophthalmologica, vol. 92, no. 3, pp. 276-281, 2014.

[66] A. Neri, R. Leaci, J. C. Zenteno, C. Casubolo, E. Delfini, and C. Macaluso, "Membrane frizzled-related protein generelated ophthalmological syndrome: 30-month follow-up of a sporadic case and review of genotype-phenotype correlation in the literature," Molecular Vision, vol. 18, pp. 2623-2632, 2012.

[67] R. Ayala-Ramirez, F. Graue-Wiechers, V. Robredo, M. AmatoAlmanza, I. Horta-Diez, and J. C. Zenteno, "A new autosomal recessive syndrome consisting of posterior microphthalmos, retinitis pigmentosa, foveoschisis, and optic disc drusen is caused by a MFRP gene mutation," Molecular Vision, vol. 12, pp. 1483-1489, 2006.

[68] J. C. Zenteno, B. Buentello-Volante, M. A. Quiroz-González, and M. A. Quiroz-Reyes, "Compound heterozygosity for a novel and a recurrent MFRP gene mutation in a family with the nanophthalmos-retinitis pigmentosa complex," Molecular Vision, vol. 15, pp. 1794-1798, 2009.
[69] A. Orr, M. P. Dubé, J. C. Zenteno et al., "Mutations in a novel serine protease PRSS56 in families with nanophthalmos," Molecular Vision, vol. 17, pp. 1850-1861, 2011.

[70] A. J. Lotery, S. G. Jacobson, G. A. Fishman et al., "Mutations in the CRB1 gene cause Leber congenital amaurosis," Archives of Ophthalmology, vol. 119, no. 3, pp. 415-420, 2001.

[71] S. G. Jacobson, A. V. Cideciyan, T. S. Aleman et al., "Crumbs homolog 1 (CRB1) mutations result in a thick human retina with abnormal lamination," Human Molecular Genetics, vol. 12, no. 9, pp. 1073-1078, 2003.

[72] A. I. den Hollander, J. R. Heckenlively, L. I. van den Born et al., "Leber congenital amaurosis and retinitis pigmentosa with Coats-like exudative vasculopathy are associated with mutations in the crumbs homologue 1 (CRB1) gene," American Journal of Human Genetics, vol. 69, no. 1, pp. 198-203, 2001.

[73] H. Abouzeid, Y. Li, I. H. Maumenee, S. Dharmaraj, and O. Sundin, "A G1103R mutation in CRB1 is co-inherited with high hyperopia and Leber congenital amaurosis," Ophthalmic Genetics, vol. 27, no. 1, pp. 15-20, 2006.

[74] C. C. Paun, B. J. Pijl, A. M. Siemiatkowska et al., "A novel crumbs homolog 1 mutation in a family with retinitis pigmentosa, nanophthalmos, and optic disc drusen," Molecular Vision, vol. 18, pp. 2447-2453, 2012.

[75] J. C. Zenteno, B. Buentello-Volante, R. Ayala-Ramirez, and C. Villanueva-Mendoza, "Homozygosity mapping identifies the Crumbs homologue 1 (Crb1) gene as responsible for a recessive syndrome of retinitis pigmentosa and nanophthalmos," American Journal of Medical Genetics Part A, vol. 155A, no. 5, pp. 1001-1006, 2011.

[76] C. J. Boon, B. J. Klevering, B. P. Leroy, C. B. Hoyng, J. E. Keunen, and A. I. den Hollander, "The spectrum of ocular phenotypes caused by mutations in the BEST1 gene," Progress in Retinal and Eye Research, vol. 28, no. 3, pp. 187-205, 2009.

[77] L. Toto, C. J. Boon, L. Di Antonio et al., "Bestrophinopathy: a spectrum of ocular abnormalities caused by the c.614T $>C$ mutation in the BEST1 gene," Retina, vol. 36, no. 8, pp. 1586-1595, 2016.

[78] E. Wittström, V. Ponjavic, M. L. Bondeson, and S. Andréasson, "Anterior segment abnormalities and angle-closure glaucoma in a family with a mutation in the BEST1 gene and Best vitelliform macular dystrophy," Ophthalmic Genetics, vol. 32, no. 4, pp. 217-227, 2011.

[79] J. Yardley, B. P. Leroy, N. Hart-Holden et al., "Mutations of VMD2 splicing regulators cause nanophthalmos and autosomal dominant vitreoretinochoroidopathy (ADVIRC)," Investigative Ophthalmology and Visual Science, vol. 45, no. 10, pp. 3683-3689, 2004.

[80] B. A. Lafaut, B. Loeys, B. P. Leroy, W. Spileers, J. J. De Laey, and P. Kestelyn, "Clinical and electrophysiological findings in autosomal dominant vitreoretinochoroidopathy: report of a new pedigree," Graefe's Archive for Clinical and Experimental Ophthalmology, vol. 239, no. 8, pp. 575-582, 2001.

[81] R. Burgess, I. D. Millar, B. P. Leroy et al., "Biallelic mutation of BEST1 causes a distinct retinopathy in humans," American Journal of Human Genetics, vol. 82, no. 1, pp. 19-31, 2008.

[82] R. Burgess, R. E. MacLaren, A. E. Davidson et al., "ADVIRC is caused by distinct mutations in BEST1 that alter pre-mRNA splicing," Journal of Medical Genetics, vol. 46, no. 9, pp. 620-625, 2009.

[83] C. J. Boon, L. I. van den Born, L. Visser et al., "Autosomal recessive bestrophinopathy: differential diagnosis and treatment options," Ophthalmology, vol. 120, no. 4, pp. 809-820, 2013. 
[84] A. E. Davidson, P. I. Sergouniotis, R. Burgess-Mullan et al., "A synonymous codon variant in two patients with autosomal recessive bestrophinopathy alters in vitro splicing of BEST1," Molecular Vision, vol. 16, pp. 2916-2922, 2010.

[85] C. Crowley, R. Paterson, T. Lamey et al., "Autosomal recessive bestrophinopathy associated with angle-closure glaucoma," Documenta Ophthalmologica, vol. 129, no. 1, pp. 57-63, 2014.

[86] H. Li, J. X. Wang, C. Y. Wang et al., "Localization of a novel gene for congenital nonsyndromic simple microphthalmia to chromosome 2q11-14," Human Genetics, vol. 122, no. 6, pp. 589-593, 2008. 


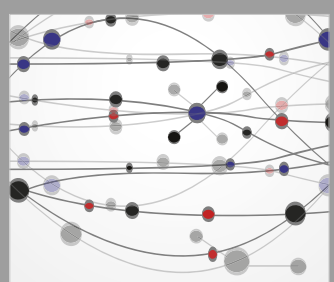

The Scientific World Journal
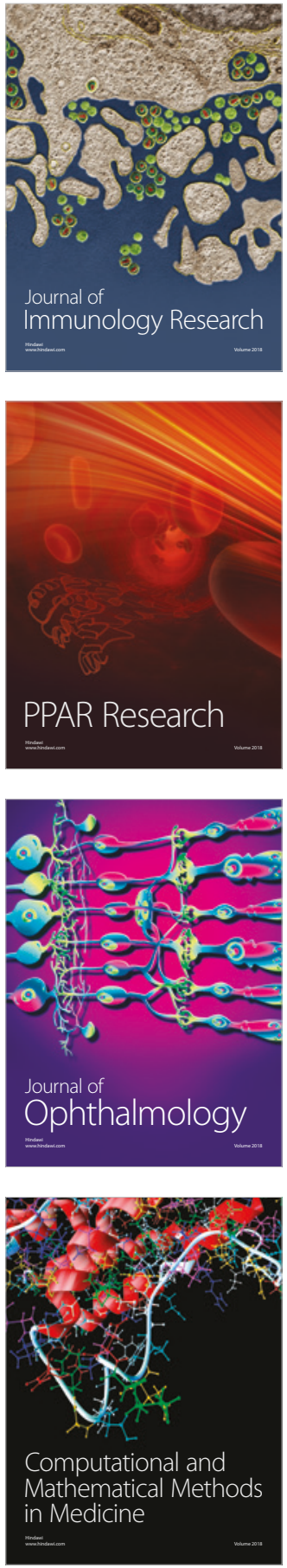

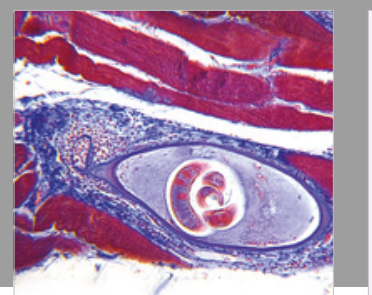

Gastroenterology Research and Practice

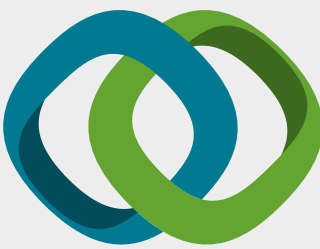

\section{Hindawi}

Submit your manuscripts at

www.hindawi.com
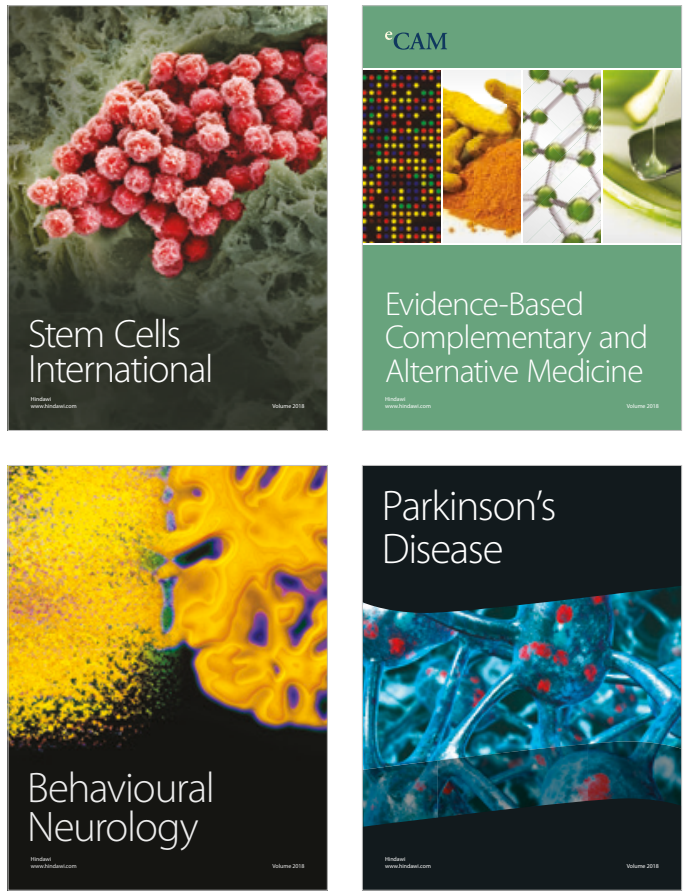

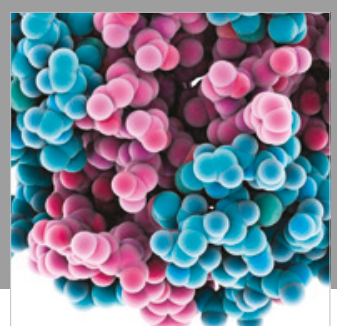

ournal of

Diabetes Research

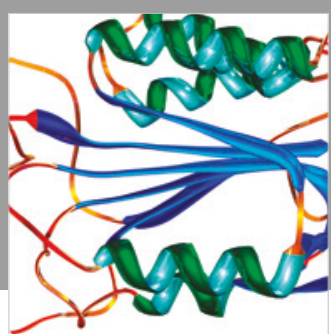

Disease Markers
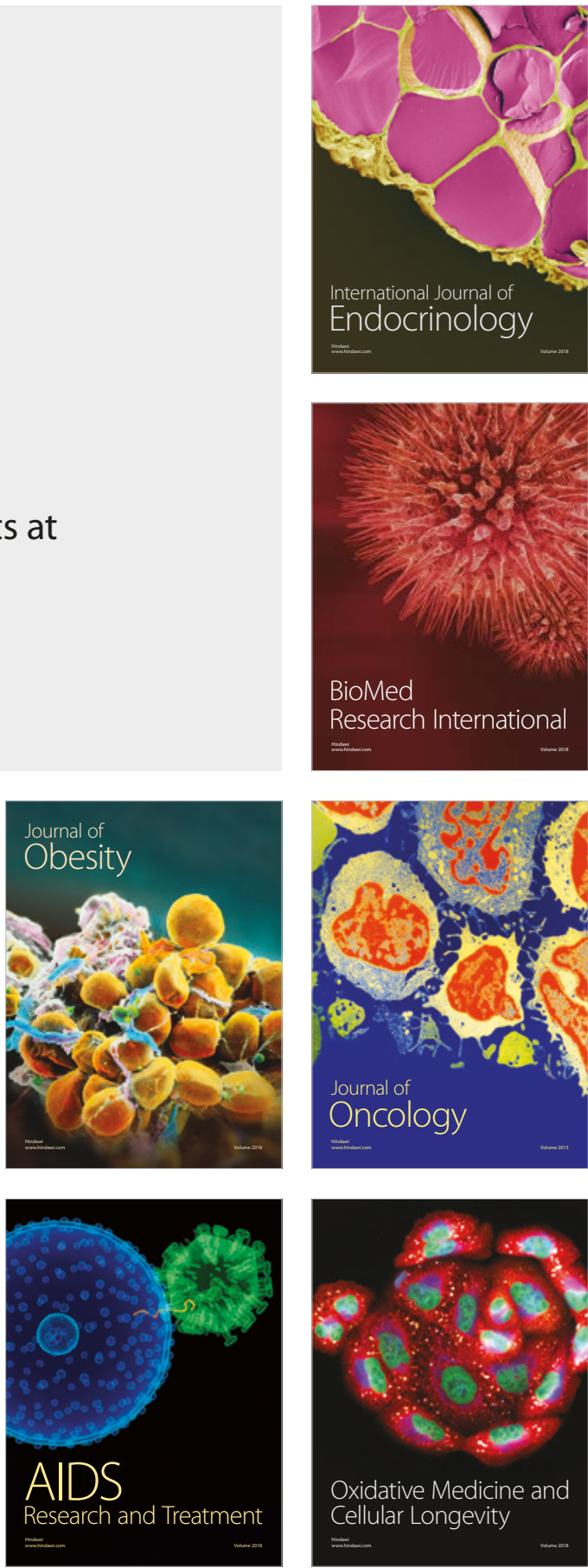